УДК 665.64.097.3

ИССЛЕДОВАНИЕ АКТИВНОСТИ КАТАЛИЗАТОРА

КАТАЛИТИЧЕСКОГО КРЕКИНГА

НА УСТАНОВКЕ ЛИНТЕЛ МАК-10

\title{
RESEARCH OF CATALYTIC CRACKING CATALYST ACTIVITY \\ AT LINTEL MAC-10 UNIT
}

\author{
А.М. Мунасыпова, А.М. Рахмангулова, А.И. Ахунов, \\ О.Ю. Белоусова, Р.Ш. Япаев
}

Уфимский государственный нефтяной технический университет, г. Уфа, Российская Федерация

\author{
Alina M. Munasypova, Aigul M. Rakhmangulova, \\ Airat I. Akhunov, Olga Yu. Belousova, Rustem Sh. Yapaev \\ Ufa State Petroleum Technological University, \\ Ufa, Russian Federation \\ e-mail: rustem_yapaev@mail.ru
}

Аннотация. Каталитический крекинг является базовым процессом, позволяющим наряду с углублением переработки нефти получать высокооктановый компонент товарных бензинов и сырье для нефтехимии. Доля бензина с установок крекинга составляет 30-50 \% от всего бензинового фонда нефтеперерабатывающего завода.

Самой важной составной частью процесса каталитического крекинга является катализатор. Современные микросферические катализаторы представляют собой сложную систему, включающую в себя ряд компонентов: матрицу из аморфных алюмосиликатов, активный компонент - цеолиты и ряд добавок, чаще всего оксидов металлов, повышающих активность катализатора. Выбор катализатора процесса 
каталитического крекинга играет значительную роль в эффективной работе установки, оказывает влияние на количество и состав образующихся продуктов.

Одним из основных требований к катализатору каталитического крекинга является высокая активность с необходимой структурой отбора продуктов крекинга.

В данной статье рассмотрен способ определения активности катализатора каталитического крекинга по ASTM D3907-03 на лабораторной установке Линтел Мак-10. Новизна работы заключается в том, что данный метод позволяет в лабораторных условиях однозначно проводить сравнение нескольких катализаторов крекинга по выходу бензина с минимальным расходом катализатора и сырья в отличие от других лабораторных установок.

Проведен ряд экспериментов с использованием вакуумного газойля в качестве сырья процесса. Исследование проводилось при температуре $482^{\circ} \mathrm{C}$ при соотношении катализатор : сырьё, равном 3. В качестве микросферического катализатора используется Октифайн 480 П Ишимбайского специализированного химического завода катализаторов, предварительно стабилизированный на лабораторной установке паровой стабилизации катализатора и подвергнутый прокалке в муфельной печи. Исследованы 6 образцов катализатора: свежий (образец № 1), стабилизированный (образец № 2), а также пропитанные солями никеля концентрациями 500, 1000, 1500, 2000 ppm (образцы № 3, № 4, № 5, № 6 соответственно). Составлены материальные балансы вакуумного газойля каталитического крекинга на Линтел МАК-10. На основании результатов построены графические зависимости, которые позволяют наглядно оценить активности исследуемых образцов свежего и стабилизированного катализатора, а также в различной степени протравленности никелем. Исследованы закономерности изменения выходов каждой фракции, сделаны общие выводы. 
Abstract. Catalytic cracking is a basic process that allows, along with the deepening of oil refining, to obtain a high-octane component of commercial gasoline and raw materials for the petrochemical industry. The share of gasoline from cracking plants is $30-50 \%$ of the total gasoline fund of the refinery.

The most important component of the catalytic cracking process is the catalyst. Modern microspherical catalysts are a complex system that includes a number of components: a matrix of amorphous aluminosilicates, the active component - zeolites and a number of additives, most often metal oxides, increasing the activity of the catalyst. The choice of catalyst for the catalytic cracking process plays a significant role in the effective operation of the plant, and affects the quantity and composition of the products formed.

One of the main requirements for a catalytic cracking catalyst is a high activity with the necessary structure of the selection of cracking products.

This article describes a method for determining the activity of a catalytic cracking catalyst according to ASTM D3907-03 in a Lintel Mac-10 laboratory setup. The novelty of the work lies in the fact that this method allows under laboratory conditions to unambiguously compare several cracking catalysts for the yield of gasoline with a minimum consumption of catalyst and raw materials, unlike other laboratory units.

A number of experiments using vacuum gas oil as the raw material of the process have been carried out. The study was conducted at a temperature of $482^{\circ} \mathrm{C}$ with a catalyst : raw material ratio equal to 3 . The microspherical catalyst used was Ostifine $480 \mathrm{P}$ of the Ishimbay specialized chemical catalyst plant, previously stabilized in a laboratory setting for steam stabilization of the catalyst and calcined in a muffle furnace. Six catalyst samples were studied: fresh stabilized (sample No. 1), stabilized (sample No. 2), and also impregnated with nickel salts with concentrations of 500, 1000, 1500, 2000 ppm (samples No. 3 , No. 4, No. 5, No. 6, respectively). The material balances of catalytic cracking vacuum gas oil at Lintel-MAC-10 are made. On the basis of the results, graphical dependences are constructed, which allow to visually assess the 
activity of the studied samples of fresh and stabilized catalyst, as well as in various degrees of nickel etching. The regularities of changes in the yields of each fraction are investigated, general conclusions are drawn.

Ключевые слова: каталитический крекинг; активность катализатора; стандарт ASTM D3907-13; микросферический катализатор; Линтел МАК-10; Линтел УПСК-10; вакуумный газойль; Октифайн 480 П

Key words: catalytic cracking; catalyst activity; ASTM D3907-13 standard; microspherical catalyst; Lintel MAC-10; Lintel UPSK-10; vacuum gasoil; Octifine $480 \mathrm{P}$

На сегодняшний день наблюдается тенденция снижения запасов и объемов добычи легких нефтей, что влечет за собой необходимость углубления переработки нефти, а также вовлечения в переработку тяжелых нефтей и природных битумов. Поэтому необходимо создавать новые или модернизировать уже существующие процессы переработки нефти [1].

Каталитический крекинг занимает одно из ключевых мест на современном нефтеперерабатывающем заводе, являясь эффективным процессом переработки низкокачественного тяжелого сырья в ценные сжиженные газы, которые используются для производств высокооктановых компонентов бензина изомерного строения: алкилата и метил-трет-бутилового эфира, и в сырье для нефтехимии (пропанпропиленовая и бутан-бутиленовые фракции) $[2,3]$.

В качестве сырьевых компонентов каталитического крекинга используются, в том числе, вакуумные дистиллятные фракции, в процессе превращения которых происходят закоксовывание катализатора и его отравление серой и металлами (V и Ni).

На данный момент сохраняется тенденция по утяжелению фракционного состава сырья, вовлекаемого в процесс каталитического 
крекинга, что приводит к увеличению содержания в сырье ароматических соединений, серы, азота и металлов, также возрастает коксуемость сырья.

Актуальными на сегодняшний день являются задачи увеличения глубины процесса каталитического крекинга и повышения его селективности, а также сохранения активности катализатора в течение длительного периода эксплуатации [4].

Одним из базовых компонентов, вовлекаемых в товарный автобензин, является бензин каталитического крекинга, доля которого составляет около 30 \% и с развитием процесса постоянно увеличивается [5].

В настоящее время существует множество способов оценки активности катализаторов. Распространенные установки для проведения испытаний катализаторов каталитического крекинга - ACE R + компании Kayser Technology (псевдоожиженный слой катализатора), DCR компании Grace Davison (циркулирующий слой катализатора).

Целью работь является исследование активности ряда образцов катализатора каталитического крекинга по методике оценки свойств катализатора в лабораторных условиях по американскому стандарту ASTM D3907-03 [6] на установке Линтел МАK-10.

\section{Экспериментальные исследования катализатора Октифайн 480 П}

\section{Подготовка катализатора к испытанию}

Исследованы 6 образцов катализатора - свежий (образец № 1), стабилизированный (образец № 2), а также пропитанные солями никеля концентрациями 500, 1000, 1500, 2000 ppm (образцы № 3, № 4, № 5, № 6 соответственно).

Для проведения испытания образцы катализатора № 3, № 4, № 5, № 6 пропитали растворами соли никеля на установке для пропитки, нанося по 0,5 мл соли заданной концентрации с помощью шприца и вращая в течение 15 мин после каждой порции соли. Повторяли данную операцию до тех 
пор, пока не нанесли 3 мл соли на каждый образец, выгрузили полученные образцы в емкости и оставили на 24 ч. При этом были подготовлены четыре образца катализатора, протравленные никелем, с концентрациями 500, 1000, 1500, 2000 ppm соответственно.

Для сравнения активностей протравленных никелем катализаторов использовали образцы свежего и стабилизированного катализатора.

Паровую стабилизацию проводили на установке, предназначенной для предварительной стабилизации катализатора Линтел УПСК-10 в атмосфере водяного пара по ASTM D 4463-96 [7].

В таблице 1 представлена характеристика катализатора Октифайн 480 П.

Таблица 1. Характеристика катализатора

\begin{tabular}{|c|c|}
\hline Характеристики & Значения \\
\hline Потери при прокаливании, \% масс. & 14,80 \\
\hline 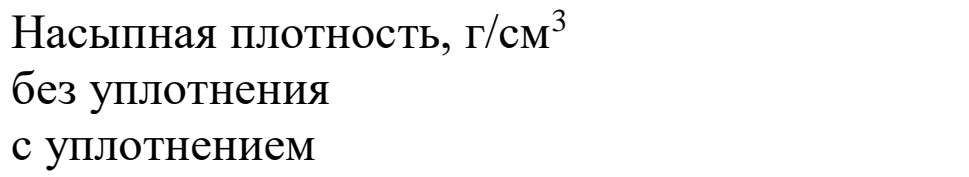 & $\begin{array}{l}0,68 \\
0,76\end{array}$ \\
\hline $\begin{array}{l}\text { Химический состав, \% масс. } \\
\mathrm{Na}_{2} \mathrm{O} \text {, не более } \\
\mathrm{Al}_{2} \mathrm{O}_{3} \text {, не менее } \\
\mathrm{Re}_{2} \mathrm{O}_{3}, \text { не менее }\end{array}$ & $\begin{array}{c}0,3 \\
40,0 \\
0,7\end{array}$ \\
\hline 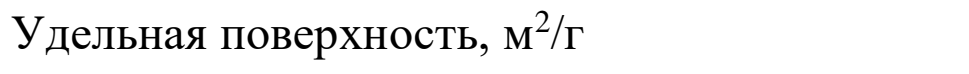 & 290,59 \\
\hline Микроактивность (ASTM D3907-03), \% масс. & 68,45 \\
\hline
\end{tabular}

Схема лабораторной установки приведена на рисунке 1. 


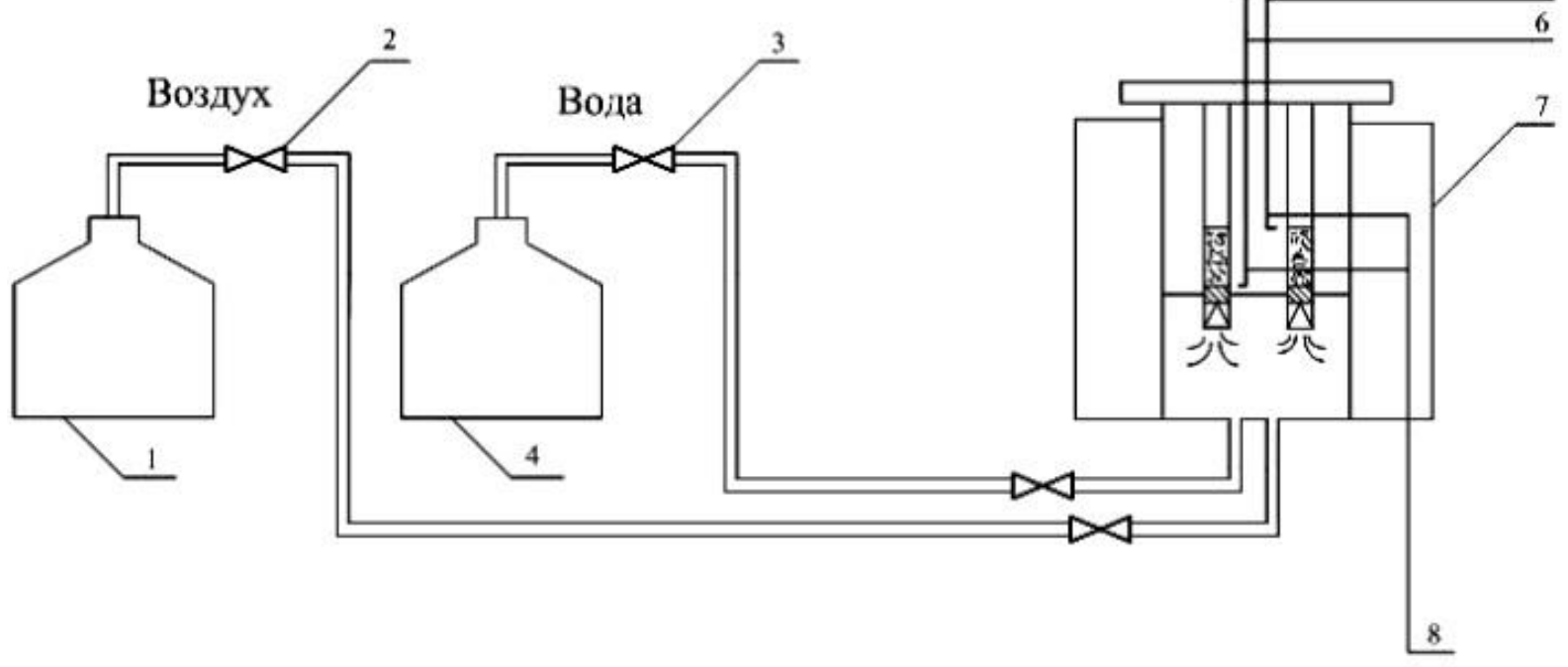

1 - блок подачи воздуха; 2 - клапан подачи воздуха;

3 - клапан подачи воды; 4 - бак с дистиллированной водой;

5, 6 - термопары; 7 - печь; 8 - текущая температура в реакторе

Рисунок 1. Схема установки паростабилизации катализатора

Стабилизация катализатора в среде водяного пара проводилась при условиях, указанных в таблице 2.

Таблица 2. Условия проведения паровой стабилизации катализатора

\begin{tabular}{|l|l|}
\hline \multicolumn{1}{|c|}{ Параметры } & \multicolumn{1}{|c|}{ Значения } \\
\hline Температура паровой стабилизации, ${ }^{\circ} \mathrm{C}$ & 760 \\
\hline Продолжительность стабилизации, ч & 5 \\
\hline Расход пара, см ${ }^{3 / \mathrm{c}}$ & 3,25 \\
\hline Высота слоя катализатора, см & 5 \\
\hline Объем стабилизируемого катализатора, мл & 50 \\
\hline
\end{tabular}

Для обеспечения удаления влаги из пор катализатора его нужно подвергнуть термической обработке.

После проведенного испытания тигли с образцами катализаторов отправляем на прокаливание в печь по схеме:

1) при температуре $120 \pm 20^{\circ} \mathrm{C}$ в течение 1 ч;

2) при $120-380{ }^{\circ} \mathrm{C}$ нагреваем в течение 1 ч (поднимаем температуру 
каждые 15 мин на $85^{\circ} \mathrm{C}$ до $\left.380^{\circ} \mathrm{C}\right)$;

3) при температуре $380{ }^{\circ} \mathrm{C}$ в течение 3 ч;

4) остужаем до температуры $120-150{ }^{\circ} \mathrm{C}$, затем убираем в эксикатор. Для более быстрого охлаждения печи приоткрываем дверцу и постепенно остужаем до $120-150{ }^{\circ} \mathrm{C}$.

Испытание на установке Линтел МАК-10

Активность катализатора определяется по стандарту ASTM D3907-03 на установке Линтел МАК-10 (рисунок 2) [8, 9].

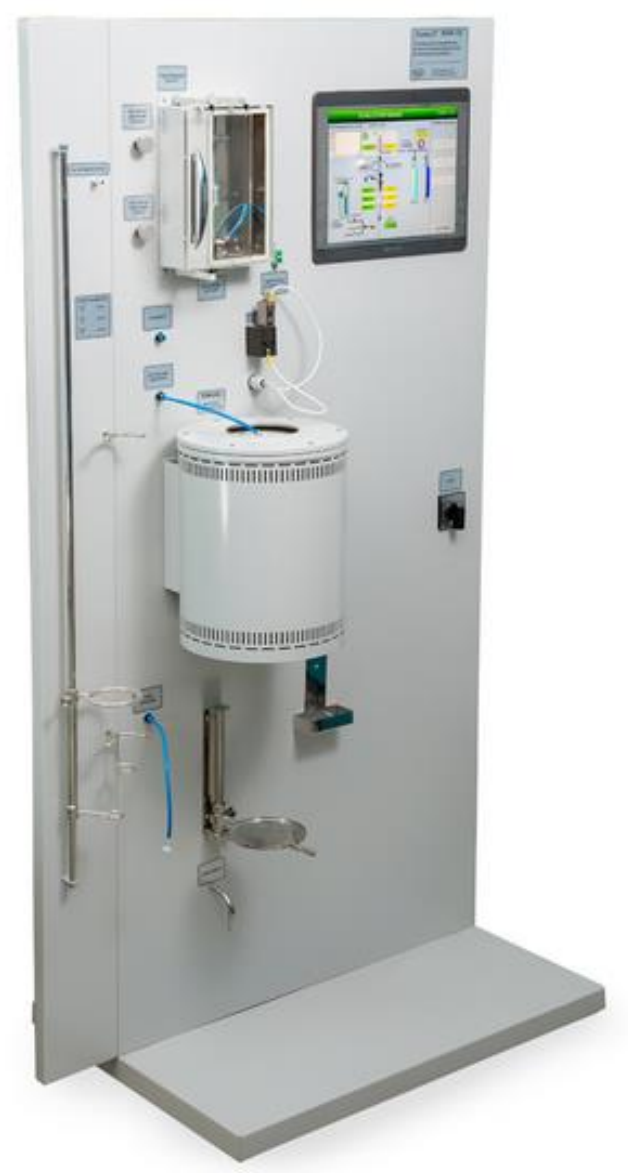

Рисунок 2. Линтел МАК-10

При выполнении экспериментов по данному методу используется вертикальный проточный реактор постоянного сечения цилиндрической формы. 
Нержавеющая сталь марки AISI 316Tі является главной составляющей корпуса реактора, что позволяет повысить его прочность. Неподвижный слой катализатора и цилиндрического стального вкладыша с впаянным капилляром, предназначенным для подачи сырья, располагается сверху кварцевого слоя. Снизу крепится приемник для сбора жидких продуктов с помощью прокладки из термостойкой резины и накидной гайки.

Активность оценивается в соответствии со стандартом по выходу бензина (температура кипения $200{ }^{\circ} \mathrm{C}$ ), полученного при крекинге вакуумного газойля [10].

Реакторную систему продували азотом с расходом 30 мл/мин. Процесс проводили при температуре $482{ }^{\circ} \mathrm{C}$, отношение катализатор : сырье - 3 .

Технологическая схема установки показана на рисунке 3.

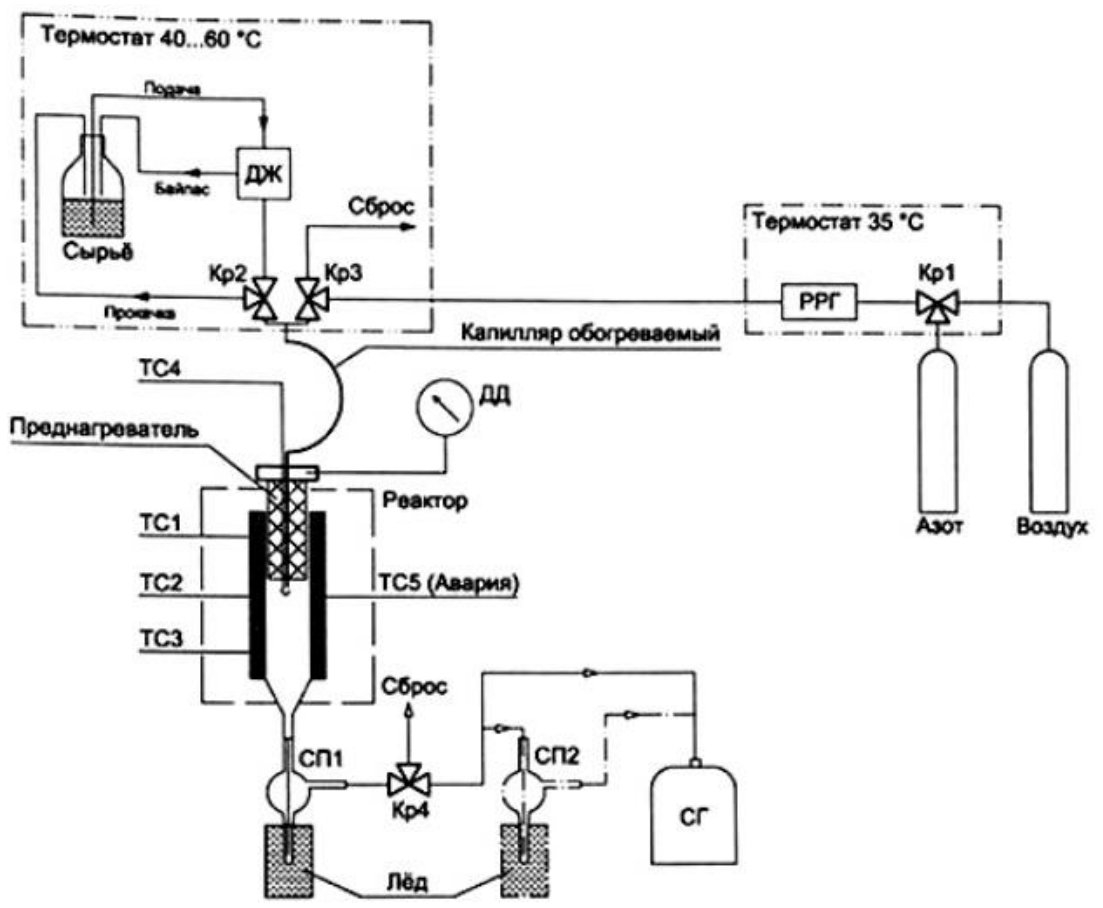

Кр1-Кр4 - краны
трехходовые
двухпозиционные;
ТС1-ТС5 -
термопары;
ДЖ - дозатор
жидкости;
РРГ - регулятор
расхода газа;
ДЦ - датчик давления;
СП1 - основной
сборник жидкого
продукта;
СП2 -
дополнительный
сборник жидкого
продукта;
СГ - сборник газа

Рисунок 3. Технологическая схема лабораторной установки каталитического крекинга

В таблице 3 представлены исходные данные для Линтел МАК-10. 
Таблица 3. Исходные данные. Параметры процесса

\begin{tabular}{|c|c|}
\hline Сырьё & Стандартный вакуумный газойль \\
\hline Катализатор & Octifine $480 \mathrm{P}$ \\
\hline Температура в реакторе & $482^{\circ} \mathrm{C}$ \\
\hline \multirow{3}{*}{ Температура печи } & $482,1^{\circ} \mathrm{C}$ \\
\hline & $483,2^{\circ} \mathrm{C}$ \\
\hline & $484,3^{\circ} \mathrm{C}$ \\
\hline Расход азота на продувку & 30 мл/мин \\
\hline $\begin{array}{l}\text { Продолжительность } \\
\text { предварительной продувки }\end{array}$ & 30 мин \\
\hline $\begin{array}{l}\text { Продолжительность завершающей } \\
\text { продувки }\end{array}$ & 15 мин \\
\hline Масса вводимого сырья & $1,33 \Gamma$ \\
\hline Время дозирования сырья & $75 \mathrm{c}$ \\
\hline $\begin{array}{l}\text { Количество загруженного } \\
\text { катализатора }\end{array}$ & 4,0138 г \\
\hline
\end{tabular}

Результаты эксперимента

В таблице 4 представлены материальные балансы стандартного вакуумного газойля каталитического крекинга при применении свежего катализатора, стабилизированного на установке паростабилизации и при различной степени протравленности никелем.

На рисунках 4-6 представлены графики зависимости выхода продуктов от активности образцов катализатора.

Таблица 4. Материальные балансы вакуумного газойля каталитического крекинга на Линтел МАК-10

\begin{tabular}{|c|c|c|c|c|c|c|}
\hline \multirow{4}{*}{$\begin{array}{l}\text { Продукты, } \\
\text { \% масс. }\end{array}$} & \multicolumn{6}{|c|}{ Образец катализатора } \\
\hline & \multirow{3}{*}{ Свежий } & \multirow{3}{*}{ Стабилизированный } & \multicolumn{4}{|c|}{ Содержащий никель, \% } \\
\hline & & & 500 & 1000 & 1500 & 2000 \\
\hline & & & $\mathrm{ppm}$ & ppm & ppm & $\mathrm{ppm}$ \\
\hline Газы & 7,3 & 6,32 & 3,98 & 4,08 & 4,15 & 4,22 \\
\hline Катализат & 91,3 & 90,6 & 90,43 & 90,3 & 90,22 & 90,1 \\
\hline $\begin{array}{l}\text { Кокс } \\
\text { потери }\end{array}$ & 1,4 & 3,08 & 5,59 & 5,62 & 5,63 & 5,68 \\
\hline
\end{tabular}




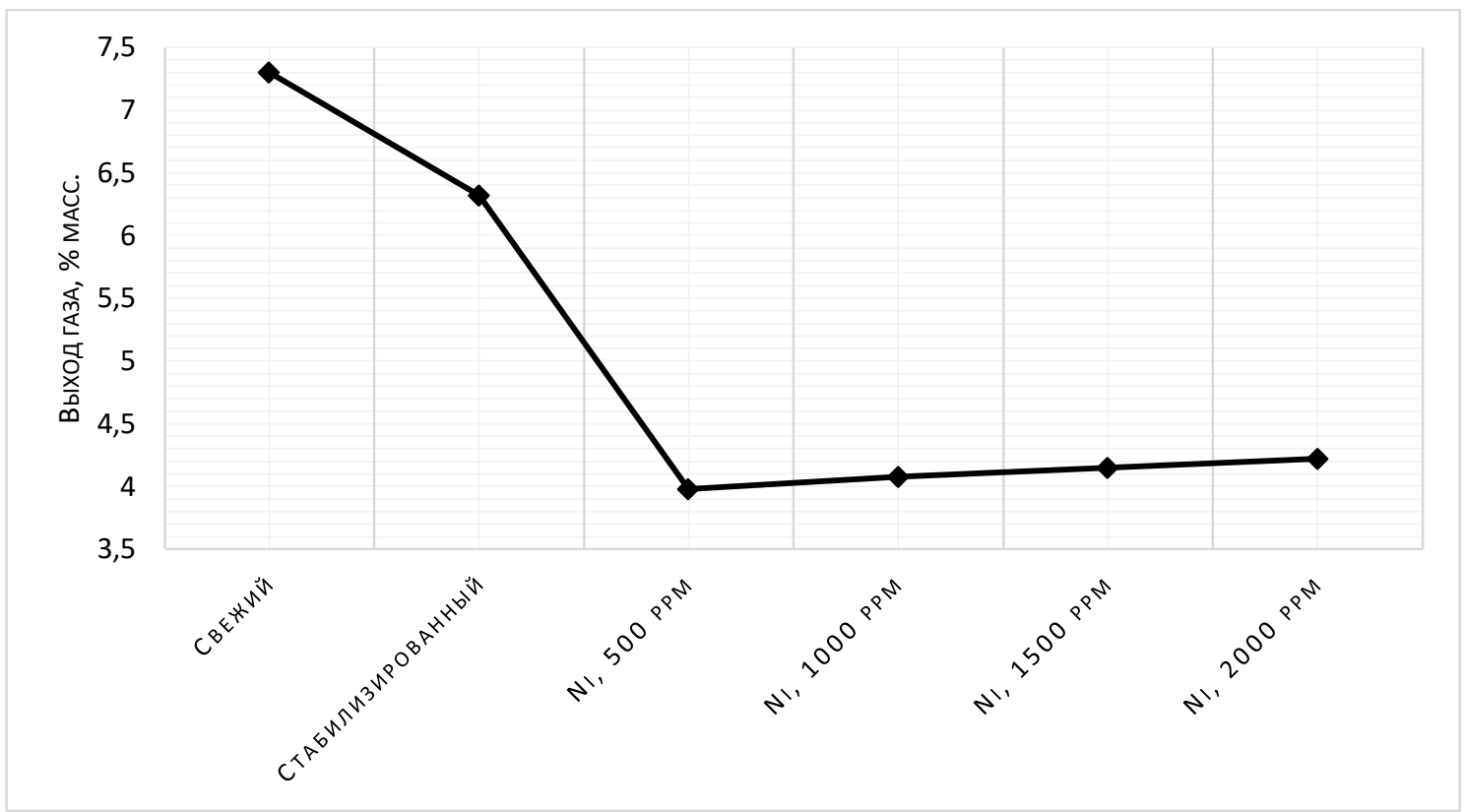

Рисунок 4. График зависимости выхода газа от исследуемых образцов катализатора

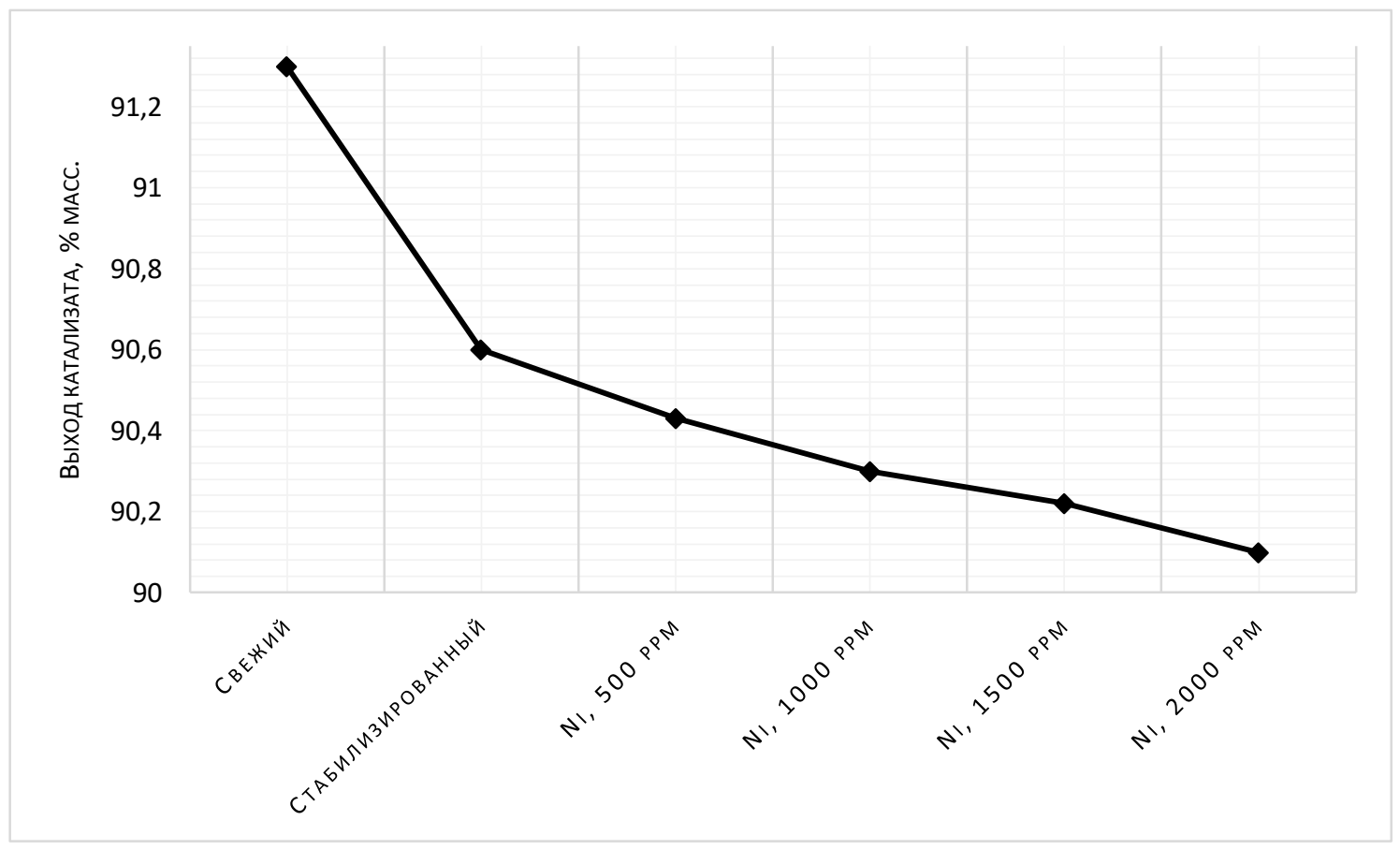

Рисунок 5. График зависимости выхода катализата от исследуемых образцов катализатора 


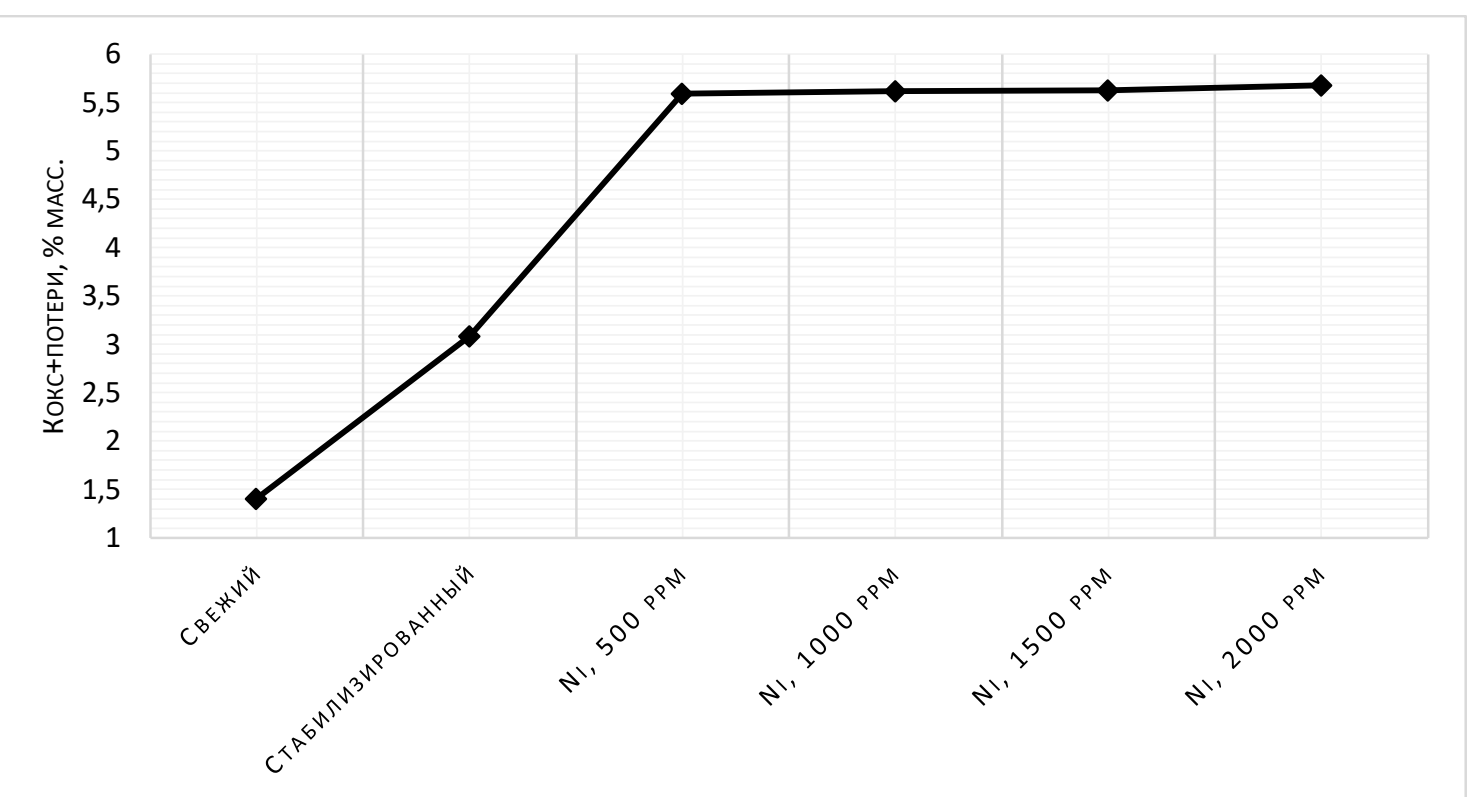

Рисунок 6. График зависимости кокса и потерь от исследуемых образцов катализатора

Обсуждение результатов

1. Активность свежего катализатора значительно выше стабилизированного, но при его применении наблюдается повышенное закоксовывание катализатора, что приводит к меньшему межрегенерационному пробегу, так как поры катализатора забиваются коксом.

2. При использовании свежего катализатора выход газа больше, чем при использовании стабилизированного. При увеличении степени протравленности никелем содержание газа увеличивается, поскольку никель обладает гидрирующими/дегидрирующими свойствами, что способствует протеканию реакций дегидрогенизации в процессе крекинга и приводит к увеличению легких газов за счет уменьшения количества бензина.

3. При увеличении степени протравленности катализатора резко снижается выход катализата, являющегося ценным продуктом 
каталитического крекинга, поскольку в дальнейшем он используется для производства моторных топлив.

4. В зависимости от степени протравленности катализатора наблюдается рост степени отложения кокса на катализаторе при увеличении концентрации никеля в образцах. Следовательно, сырье, используемое в процессе каталитического крекинга, должно быть предварительно подготовленным, так как отравление металлами, такими как никель, ванадий, является необратимым и приводит к отрицательному воздействию на активность, а также селективность катализатора.

\section{Выводы}

1. Проведены экспериментальные исследования с целью выявления закономерностей выхода продуктов каталитического крекинга от активности катализатора Octifine 480 Р по американскому стандарту ASTM D3907-03 на лабораторной установке Линтел Мак-10.

2. Отмечено, что лабораторная установка Линтел МАК-10 позволяет с высокой точностью оценить качество вакуумного газойля и катализатора с минимальными затратами, так как объемы исследуемых проб малы.

3. На основе проведенных исследований и анализа литературных источников установлено, что в промышленном масштабе необходимо контролировать изменение выхода продуктов, так как по уменьшению выхода бензина можно судить об уменьшении активности катализатора. В зависимости от увеличения содержания никеля и, следовательно, увеличения отложений кокса активность катализатора снижается. 


\section{Список используемых источников}

1. Гильмутдинов А.Т., Хисамова Л.3. Обзор современных катализаторов, используемых в процессах каталитического крекинга // Электронный журнал «Вопросы науки и образования». 2019. № 5. С. 10-14. URL: $\quad$ https://scientificpublication.ru/images/PDF/2019/50/Questions_of_ science_and_education-5-50.pdf (дата обращения: 23.10.2019). DOI: 10.24411/2542-081X-2019-10502.

2. Ершов Д.С., Хафизов А.Р., Мустафин И.А. Современное состояние и тенденции развития процесса каталитического крекинга // Фундаментальные исследования. 2017. № 12-2. С. 282-286.

3. Кондрашев Д.О. Развитие технологии каталитического крекинга: от неподвижного к псевдоожиженному слою // Нефтепереработка и нефтехимия. 2018. № 6. С. 3-9.

4. Чудинов А.Н., Денисламова Е.С., Кожевников Д.Н. Сравнительная оценка параметров и активности цеолитных катализаторов крекинга в псевдоожиженном слое // Вестник Пермского национального исследовательского политехнического университета. Химическая технология и биотехнология. 2017. № 4. C. 171-183. DOI: 10.15593/22249400/2017.4.12.

5. Жуков К.Г., Акбарова Э.И., Иванова К.В. Экологические аспекты применения бензина каталитического крекинга и методы улучшения его качества // Сетевое издание «Нефтегазовое дело». 2019. № 1. С. 218-233. URL: http://ogbus.ru/files/ogbus/issues/1_2019/ogbus_1_2019_p218-233.pdf (дата обращения: 26.10.2019). DOI: 10.17122/ogbus-2019-1-218-233.

6. ASTM D3907/D3907M. Standard Test Method for Testing Fluid Catalytic Cracking (FCC) Catalysts by Microactivity Test // ASTM International. URL: https://www.astm.org/Standards/D3907.htm (дата обращения: 28.10.2019). 
7. ASTM D 4463-96. Standard Guide for Metals Free Steam Deactivation of Fresh Fluid Cracking Catalysts // ASTM International. URL: https://www.astm.org/DATABASE.CART/HISTORICAL/D4463-96.htm (дата обращения: 27.10.2019).

8. Белоусова О.Ю., Япаев Р.Ш., Мунасыпова А.М., Рахмангулова А.М. Изучение закономерностей процесса каталитического крекинга на лабораторной установке «Линтел МАК-10». Уфа: УГНТУ, 2018. URL: http://bibl.rusoil.net (дата обращения: 22.10.2019).

9. Официальный сайт Нефтехимавтоматики. URL: http:// www.bashnxa.ru/catalog/catalizators-laboratiry/catalizators-laboratiry_30.html (дата обращения: 22.10.2019).

10. Минхайрова М.Т., Халикова Д.Г., Шаяхметов А.М. Исследование активности микросферических катализаторов // Сетевое издание «Нефтегазовое дело». 2018. № 2. С. 6-15. URL: http://ogbus.ru/files/ ogbus/issues/2_2018/ogbus_2_2018_p6-15_MinhayrovaMT_ru.pdf （дата обращения: 28.10.2019). DOI: 10.17122/ogbus-2018-2-6-15.

\section{References}

1. Gilmutdinov A.T., Khisamova L.Z. Obzor sovremennykh katalizatorov, ispol'zuemykh $\mathrm{v}$ protsessakh kataliticheskogo krekinga [Overview of Modern Catalysts Used in Catalytic Cracking Processes]. Elektronnyi zhurnal «Voprosy nauki i obrazovaniya» - Science and Education, 2019, No. 5, pp. 10-14. URL: https://scientificpublication.ru/images/PDF/2019/50/Questions_of_science_and_ education-5-50.pdf (data obrashcheniya: 23.10.2019). DOI: 10.24411/2542081Kh-2019-10502. [in Russian].

2. Ershov D.S., Khafizov A.R., Mustafin I.A. Sovremennoe sostoyanie i tendentsii razvitiya protsessa kataliticheskogo krekinga [Current State and Trends in the Development of the Catalytic Cracking Process]. Fundamental'nye issledovaniya - Fundamental Research, 2017, No. 12-2, pp. 282-286. [in Russian]. 
3. Kondrashev D.O. Razvitie tekhnologii kataliticheskogo krekinga: ot nepodvizhnogo k psevdoozhizhennomu sloyu [Development of Catalytic Cracking Technology: From Still Layer to Fluid Type]. Neftepererabotka i neftekhimiya - Oil Processing and Petrochemistry, 2018, No. 6, pp. 3-9. [in Russian].

4. Chudinov A.N., Denislamova E.S., Kozhevnikov D.N. Sravnitel'naya otsenka parametrov $\mathrm{i}$ aktivnosti tseolitnykh katalizatorov krekinga $\mathrm{v}$ psevdoozhizhennom sloe [Fluid Catalytic Cracking Zeolie Catalysts Parameters and Activity Evaluation]. Vestnik Permskogo natsional'nogo issledovatel'skogo politekhnicheskogo universiteta. Khimicheskaya tekhnologiya i biotekhnologiya - PNRPU Bulletin. Chemical Technology and Biotechnology, 2017, No. 4, pp. 171-183. DOI: 10.15593/2224-9400/2017.4.12. [in Russian].

5. Zhukov K.G., Akbarova E.I., Ivanova K.V. Ekologicheskie aspekty primeneniya benzina kataliticheskogo krekinga i metody uluchsheniya ego kachestva [Environmental Aspects of Using the Catalytic Cracking Gasoline and Methods to Improve its Quality]. Setevoe izdanie «Neftegazovoe delo»-Online Edition «Oil and Gas Business», 2019, No. 1, pp. 218-233. URL: http://ogbus.ru/files/ogbus/issues/1_2019/ogbus_1_2019_p218-233.pdf (accessed 26.10.2019). DOI: 10.17122/ogbus-2019-1-218-233. [in Russian].

6. ASTM D3907/D3907M. Standard Test Method for Testing Fluid Catalytic Cracking (FCC) Catalysts by Microactivity Test. ASTM International. URL: https://www.astm.org/Standards/D3907.htm (accessed 28.10.2019).

7. ASTM D 4463-96. Standard Guide for Metals Free Steam Deactivation of Fresh Fluid Cracking Catalysts. ASTM International. URL: https://www.astm.org/DATABASE.CART/HISTORICAL/D4463-96.htm (accessed 27.10.2019).

8. Belousova O.Yu., Yapaev R.Sh., Munasypova A.M., Rakhmangulova A.M. Izuchenie zakonomernostei protsessa kataliticheskogo krekinga na laboratornoi ustanovke «Lintel MAK-10» [Studying the Laws of the Catalytic Cracking Process at the Lintel MAK-10 Laboratory Facility]. Ufa, UGNTU, 2018. URL: http://bibl.rusoil.net/ (accessed 22.10.2019). [in Russian]. 
9. Official Website of Neftekhimavtomatika. URL: http:// www.bashnxa.ru/catalog/catalizators-laboratiry/catalizators-laboratiry_30.html (accessed 22.10.2019). [in Russian].

10. Minkhairova M.T., Khalikova D.G., Shayakhmetov A.M. Issledovanie aktivnosti mikrosfericheskikh katalizatorov [Investigation of the Activity of Micro-Spherical Catalysts]. Setevoe izdanie «Neftegazovoe delo»-Online Edition «Oil and Gas Business», 2018, No. 2, pp. 6-15. URL: http://ogbus.ru/files/ogbus/issues/2_2018/ogbus_2_2018_p6-

15_MinhayrovaMT_ru.pdf (accessed 28.10.2019). DOI: 10.17122/ogbus-20182-6-15. [in Russian].

\section{Сведения об авторах}

\section{About the authors}

Мунасыпова Алина Мидхатовна, студент кафедры «Технология нефти и газа», УГНТУ, г. Уфа, Российская Федерация

Alina M. Munasypova, Student of Oil and Gas Processing Department, USPTU, Ufa, Russian Federation

e-mail: alinchik22085@mail.ru

Рахмангулова Айгуль Маратовна, студент кафедры «Технология нефти и газа», УГНТУ, г. Уфа, Российская Федерация

Aigul M. Rakhmangulova, Student Oil and Gas Processing Department, USPTU, Ufa, Russian Federation

e-mail: rahmangulova2013@yandex.ru

Ахунов Айрат Ильшатович, студент кафедры «Технология нефти и газа», УГНТУ, г. Уфа, Российская Федерация

Airat I. Akhunov, Student of Oil and Gas Processing Department, USPTU, Ufa, Russian Federation 
Белоусова Ольга Юрьевна, кандидат технических наук, доцент кафедры «Технология нефти и газа», УГНТУ, г. Уфа, Российская Федерация

Olga Yu. Belousova, Candidate of Engineering Sciences, Assistant Professor of Oil and Gas Processing Department, USPTU, Ufa, Russian Federation e-mail: rustem_yapaev@mail.ru

Япаев Рустем Шамильевич, кандидат технических наук, доцент кафедры «Технология нефти и газа», УГНТУ, г. Уфа, Российская Федерация

Rustem Sh. Yapaev, Candidate of Engineering Sciences, Assistant Professor of Oil and Gas Processing Department, USPTU, Ufa, Russian Federation e-mail: rustem_yapaev@mail.ru 